\title{
EVALUASI SISTEM PENGENDALIAN INTERNAL PADA RUMAH SAKIT PKU MUHAMMADIYAH NANGGULAN
}

\author{
Rigel Nurul Fathah, Muhammad \\ Khozin Universitas Aisyiyah \\ Yogyakarta \\ rigelnurul@unisayogya.ac.id
}

\begin{abstract}
This community service was carried out in collaboration with PKU Nanggulan Hospital with Aisyiyah University in Yogyakarta. Previously the team coordinated and need assessment so that it was known the condition of PKU Nanggulan Hospital through observation and interviews with the management of PKU Nanggulan Hospital as well as sharing about what obstacles faced by the management of PKU Nanggulan Hospital so far. Based on observations and direct interviews with partners found problems encountered are weak internal control at PKU Nanggulan Hospital, weaknesses include: (1) There is no separation of duties between gauze, financial and bookkeeping sections (2) There is no Standard Operating Procedure (SOP) that is clear between parts (3) The absence of a clear job description between parts (4) Financial recording is still simple using cash basis so that it only records cash income and expenses. this service has a program that is expected to be a solution to the problems experienced by partners. The solution program offered is training and socialization, namely giving understanding to management in the form of training and outreach to the management of PKU Nanggulan Hospital regarding the importance of Internal Control in order to improve performance so that it can provide good health services, have relevant and accurate information, and human resources the professional.
\end{abstract}

Keywords : International Control System, Hospital

\section{PENDAHULUAN}

Dunia medis saat ini mengalami perkembangan begitu pesat baik dari pelayanan, maupun penemuan- penemuan dalam bidang pengobatan. Menurut World Health Organization (WHO), Rumah sakit adalah bagian integral dari suatu organisasi sosial dan kesehatan dengan fungsi menyediakan pelayanan paripurna (komprehensif), penyembuhan penyakit (kuratif) dan pencegahan penyakit (preventif) kepada masyarakat. Karakteristik Rumah Sakit yaitu tidak hanya mencari keuntungan namun ada aspek sosial dan pelayanan kepada masyarakat tergantung jenis rumah sakit dan sumber pendanaan rumah sakit. Rumah sakit didirikan dengan tujuan memberikan suatu pelayanan kesehatan, diantaranya adalah dalam bentuk perawatan, pemeriksaan, pengobatan, tindakan medis, dan diagnostik lainnya yang dibutuhkan oleh pasien dalam batas-batas kemampuan teknologi dan sarana yang disediakan oleh rumah sakit (Maharani dkk, 2015).

Peraturan Menteri Kesehatan Nomor 147/Menkes/PER/I/2010 tentang perizinan Rumah Sakit mengelompokkan rumah sakit berdasarkan kepemilikan, yaitu rumah sakit publik dan privat. Rumah sakit publik adalah rumah sakit yang dikelola 
pemerintah, pemerintah daerah, dan badan hukum yang bersifat nirlaba. Sedangkan rumah sakit privat adalah rumah sakit yang dikelola oleh badan hukum dengan tujuan profit yang berbentuk perseroan terbatas atau persero. Rumah Sakit PKU Nanggulan merupakan rumah sakit publik swasta non profit yang dimiliki amal usaha Muhammadiyah yang bergerak di bidang kesehatan dan sosial.

Pelayanan rumah sakit yang baik meningkatkan kepercayaan dan kepuasan masyarakat yang membutuhkan layanan kesehatan. Agar mampu memberikan pelayanan kesehatan yang baik, rumah sakit harus memiliki informasi yang relevan dan akurat, serta sumber daya yang profesional. Karena adanya pelayananyang baik akan lebih meningkatkan perkembangan kegiatan usaha rumah sakit tersebut.

Untuk mencapai tujuan suatu organisasi membutuhkan suatu sistem yang bisa mengontrol, mengawasi dan mengarahkan. Salah satu upaya untuk mengarahkan, mengawasi dan sumber daya suatu organisasi adalah pengendalian internal. Menurut Romney (2015) Pengendalian internal merupakan komponen dari sistem informasi akuntansi. Pengendalian internal dapat menjadi faktor penting agar suatu sistem dapat berjalan dengan efektif. Hal ini karena pengendalian internal dapat memenuhi fungsi sistem informasi akuntansi menyangkut adanya pengendalian yang memadai untuk pengamanan aset data organisasi. Dengan demikian jika pengendalian internal di Rumah Sakit PKU Muhammadiyah Nanggulan dinyatakan kurang efektif, maka sistem informasi akuntansi yang dijalankan Rumah Sakit tidak mungkin dan kemungkinan adanya kecurangan cukup besar terjadi.

Pengabdian masyarakat ini dilaksanakan atas kerjasama dengan RS PKU Muhammadiyah Nanggulan dengan Prodi S1 Akuntansi Universitas 'Aisyiyah Yogyakarta. Sebelumnya tim dari prodi S1 Akuntansi melakukan koordinasi dan need assesment sehingga diketahui keadaan RS PKU Muhammadiyah Nanggulan melalui observasi dan wawancara dengan pihak manajemen RS PKU Muhammadiyah Nanggulan serta sharing mengenai kendala apa saja yang dihadapi oleh manajemen RS PKU Nanggulan selama ini. Kendala yang dihadapi RS PKU Muhammadiyah selama ini antara lain : (1) Terkait dengan penganggaran . Tahun 2013 RS PKU Muhaamdiyah Nanggulan terkena sanksi pajak akibat kesalahan di tahun 2010. Laporan Keuangan dan berkas yang diperiksa di kantor pajak ditemukan masih banyak terdapat kesalahan dalam hal salah hitung dan kurang bayar dikarenakan pihak RS PKU Muhammadiyah Nanggulan belum mengetahui cara pelaporan yang benar. Selain itu RS PKU Muhammadiyah Nanggulan belum menyusun Rencana Strategis (Renstra) dan Rencana Operasional (Renop) dalam hal penganggaran. (2) Terkait dengan Sistem Informasi Akuntansi. RS PKU Muhammadiyah Nanggulan menerima software tentang tarif dan data-data keuangan dari RS PKU Muhammadiyah Gamping sekitar bulan Mei 2017 untuk mendukung proses akreditasi. Sebelumnya RS PKU Muhammadiyah Nanggulan sistem akuntansimya masih manual. Oleh karena itu, dibutuhkan pendampingan dalam pelaksanaannya. (3) Terkait dengan hal pengendalian internal. RS PKU Muhammdiyah Nanggulan selama ini belum memisahkan antara bagian kasir dan bagian keuangan dan bagian pembukuan dikarenakan tidak adanya deskripsi pekerjaan (job description) yang jelas antar bagian serta tidak ada Standar Operasional Prosedur (SOP) yang dijalankan di rumah sakit tersebut. Selain itu juga belum ada otorisasi dari pihak direksi atau atasan terkait pengeluaran uang yang melebihi range (missal 1.000 .000 ke atas). Hal ini dapat memungkinkan adanya tingkat kecurangan karena pengamanan asset belum dilaksanakan dengan baik.

Berdasarkan observasi dan wawancara langsung dengan mitra dirumuskan 
permasalahan yang dihadapi mitra yaitu lemahnya pengendalian internal di RS PKU Muhammadiyah Nanggulan, kelemahan diantaranya adalah :

1. Tidak ada pemisahan tugas antara bagian kassa, bagian keuangan dan bagian pembukuan.

2. Tidak ada Standar Operasional Prosedur (SOP) yang jelas antar bagian.

3. Tidak adanya deskripsi pekerjaan (job description) yang jelas antar bagian

4. Pencatatan keuangan masih sederhana menggunakan cash basis sehingg hanya mencatat pemasukan dan pengeluaran kas.

\section{METODOLOGI}

Dari permasalahan-permasalahan yang dimiliki oleh mitra diatas, maka pengabdian ini memiliki program yang diharapkan dapat menjadi solusi bagi permasalahan yang dialami oleh mitra dengan beberapa metode antara lain :

1. Metode Ceramah

Dalam metode ini pertama-tama perlu adanya persiapan. Persiapan yang dimaksud adalah menjelaskan kepada pihak RS PKU Muhammadiyah Nanggulan tentang tujuan pengabdian masyarakat yang dijalankan dan pokok- pokok masalah yang akan dibahas dan pemateri menyajikan bahan yang berkenaan dengan pokok-pokok permasalahan.

\section{Metode FGD (Focus Group Discussion)}

Diskusi Kelompok Terarah atau Focus Group Discussion merupakan suatu proses pengumpulan informasi mengenai suatu masalah tertentu yang sangat spesifik yang dipimpin seorang narasumber atau moderator yang mendorong peserta untuk berbicara terbuka dan spontan tentang hal yang dianggap penting dan berkaitan dengan topic saat itu, dalam hal ini adalah pengendalian internal yang telah dilaksanakan di RS PKU Muhammadiyah Nanggulan.Tujuan dari diskusi kelompok terarah adalah untuk memperoleh masukan atau informasi mengenai permaslahan yang bersifat local dan spesifik.

\section{Metode Pelatihan}

Metode pelatihan yaitu memberi pemahaman kepada pihak manajemen RS PKU Nanggulan akan pentingnya Pengendalian Internal guna meningkatkan kinerja sehingga bisa memberikan pelayanan kesehatan yang baik, memiliki informasi yang relevan dan akurat, serta sumber daya manusia yang profesional. Adapun pelatihan yang dilaksanakan melalui beberapa tahapan :

a. Tim mengidentifikasi kebutuhan SOP berdasarkan data dan informasi yang diperoleh pada saat observasi

b. Tim kemudian melakukan wawancara dengan pihak manajemen untuk mendapatkan informasi terkait alur pelaksanaan tugas dan pengendalian internal yang dilakukan dan kendala apa saja yang dihadapi di RS PKU Muhammadiyah Nanggulan selama ini.

c. Tim mendesain SOP sebagai standarisasi yang dilakukan oleh seorang pegawai dalam melaksanakan pekerjaan sesuai tugasnya.

d. Setelah mendesain SOP, tim kemudian menyusun job description dan bagan organisasi sebagai bentuk pengendalian internal.

\section{HASIL, PEMBAHASAN DAN DAMPAK}

Kegiatan PKM sebelumnya diawali dengan koordinasi dan need assessment pada tanggal 2 Juni 2018. Kemudian setelah koordinasi dan need assessment, kegiatan dilanjutkan dengan pelatihan penyusunan SOP yang berjalan baik dan lancar. 
Pertemuan tatap muka dengan metode ceramah dan demonstrasi, dilanjutkan pelatihan untuk membuat SOP pada tanggal 24 Agustus 2018. Dari pukul 8.00-12.00. Peserta kegiatan berjumlah 10 orang terdiri dari pihak direksi dan karyawan bagian keuangan RS PKU Muhammadiyah Nanggulan.

Pelaksanaan kegiatan PKM ini dilakukan oleh dua (2) tim pengabdi dengan pokok bahasan:

1) Teori Pengendalian Internal

2) Kelemahan pengendalian Internal di RS PKU Muhammadiyah Nanggulan

3) Pengembangan SOP yang dibutuhkan yaitu SOP Penerimaan Kas, SOP Pengeluaran Kas dan SOP Pencatatan Kas

4) Latihan pembuatan SOP

5) Evaluasi hasil SOP yang telah disusun.

Keterbatasan waktu pertemuan mengakibatkan tidak semua materi disampaikan dengan detil.

Kegiatan yang diawali dengan ceramah dan demonstrasi ini kemudian dilanjutkan latihan. Dari kegiatan latihan, tampak bahwa pihak direksi dan karyawan belum menguasai cara pembuatan SOP. Acara kemudian dilanjutkan dengan tanya jawab. Berbagai pertanyaan diajukan secara antusias oleh para peserta dalam sesi tanya jawab. Secara garis besar pertanyaan yang diajukan oleh peserta adalah :

1) Langkah-langkah penyusunan SOP

2) Tingkat keberhasilan SOP

3) Kualitas SOP

4) Kelayakan SOP

Program pengabdian evaluasi sistem pengendalian internal berupa pelatihan pembuatan SOP yang sudah dilaksanakan ini diharapkan dapat menambah pengetahuan akan pentingnya pengendalian internal yang diterapkan di RS PKU Muhammadiyah Nanggulan. Pengendalian internal yang baik dapat menanggulangi tingkat kecurangan dan meningkatkan kinerja karyawan khususnya bagian keuangan. Manfaat yang diperoleh pihak direksi dan karyawan adalah dapat menyusun SOP sebagai bentuk pengendalian internal karena selama ini belum ada pemisahan tugas dan tanggung jawab di bagian keuangan, antara yang menerima uang, mengeluarkan uang dan pencatatan.

\section{KESIMPULAN}

1. Pengabdian masyarakat yang telah dilaksanakan merupakan evaluasi pengendalian internal berupa pelatihan penyusunan Standar Operasional Prosedur (SOP) di RS PKU Muhammadiyah Nanggulan Yogyakarta. Dengan adanya pelatihan tersebut diharapkan dapat meningkatkan pengetahuan dan pemahaman direksi dan karyawan bagian keuangan akan pentingnya pengendalian internal dalam suatu institusi perusahaan dalam hal ini rumah sakit. Pengendalian internal dapat menjadi faktor penting agar suatu sistem dapat berjalan dengan efektif. Hal ini karena pengendalian internal dapat memenuhi fungsi sistem informasi akuntansi menyangkut adanya pengendalian yang memadai untuk pengamanan aset data organisasi. Dalam hal ini tim pengabdian menyoroti bagian kas, dimana tidak adanya pemisahan tugas dan tanggung jawab antara pemasukan kas, pengeluaran kas dan pencatatan kas, sehingga disusun SOP yaitu : SOP Pemasukan Kas, SOP Pengeluaran Kas dan SOP Pencatatan Kas. 
Jurnal SEMAR Vol. 7 No. 2, 2018 hal. 32 - 38

ISSN: 2302-3937 | Copyright (C LPPM Universitas Sebelas Maret Homepage: https://jurnal.uns.ac.id/jurnal-semar

2. Pengabdian ini juga merupakan tindak lanjut penelitian tim yang sbelumnya melakukan penelitian Analisis Pengendalian Internal di tempat yang sama.

3. Pengabdian ini dapat dianggap berhasil dan sukses walaupun ada sedikit kendala yaitu adalah kurangnya waktu dan pergantian shift jaga tetapi kendaa tersebut dapat diatasi dengan baik.

\section{SARAN}

Berdasarkan evaluasi yang telah dilakukan dapat diajukan beberapa saran sebagai berikut :

1. Waktu pelaksanaan kegiatan pengabdian perlu ditambah agar tujuan dapat tercapai sepenuhnya

2. Adanya kegiatan lanjutan yang berupa pelatihan sejenis yang diselenggerakan secara periodik sehingga dapat meningkatkan kemampuan pihak direksi dan karyawan bagian keuangan dalam memahami pentingnya pengendalian internal.

\section{UCAPAN TERIMA KASIH}

Kegiatan pengabdian masyarakat ini tidak terlpas dari bantuan dan peran-peran serta berbagai pihak. Pada kesempatan ini dihaturkan ucapan terima kasih kepada pihak RS PKU Muhammadiyah Nanggulan yang telah memberikan waktu dan kesempatan kepada pihak tim kami untuk melaksanakan pengbdian dan pihak LPPM Universitas Aisyiyah yang telah memberikan dukungan atas terlaksananya pengabdian masyarakat ini.
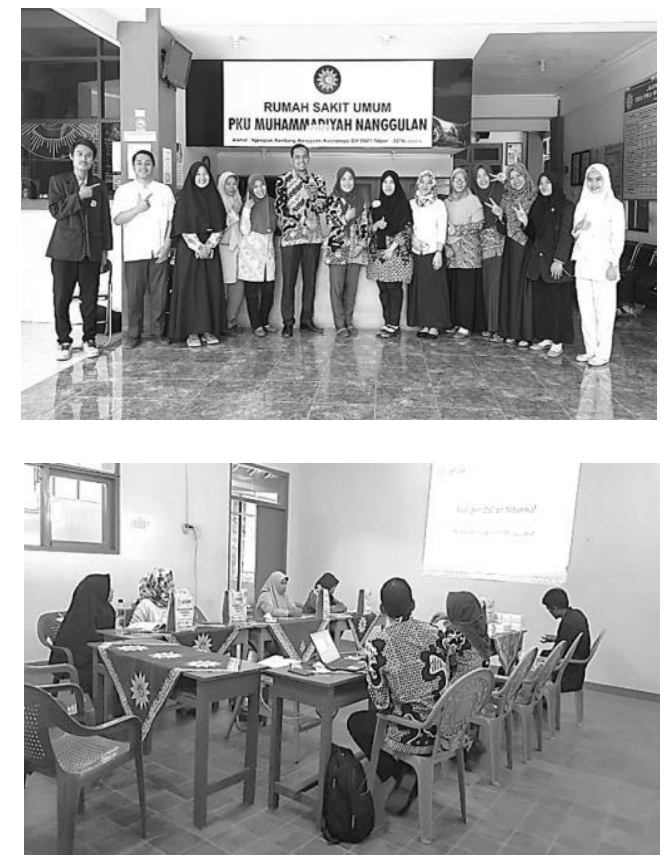

Dokumentasi foto kegiatan pengabdian masyarakat 
Jurnal SEMAR Vol. 7 No. 2, 2018 hal. 32 - 38

ISSN: 2302-3937 | Copyright (C) LPPM Universitas Sebelas Maret

Homepage: https://jurnal.uns.ac.id/jurnal-semar

\section{DAFTAR PUSTAKA}

Maharani, S. T., Kertahadi, dan Dwiatmanto. 2015. Analisis Sistem dan Prosedur Penggajian Dan Pengupahan Dalam Meningkatkan Efektivitas Pengendalian Intern Gaji Dan Upah (Studi Pada PG Kebun Agung Malang). Jurnal Administrasi Bisnis. Vol 26. (No. 1), hal 1-10.

Romney, Marshall B., dan Paul John Steinbart. 2015. Accounting Information Systems, $13^{\text {th }}$ ed, England: Pearson Educational Limited.

Nurul, Rigel. 2018. Analisis Sistem Pengendalian Internal Pada Rumah Sakit PKU Muhammadiyah Nanggulan. LPPM UNISA 